\title{
Дискусійні статті
}

УДК 617.731-005.4-036

\section{О.Д. Рудковская \\ ПРОГНОЗИРОВАНИЕ ДВУСТОРОННЕГО ПОРАЖЕНИЯ ЗРИТЕЛЬНЫХ НЕРВОВ ИШЕМИЧЕСКИМ ПРОЦЕССОМ}

Буковинский государственный медицинский университет, г. Черновцы

Резюме. Обследовано две группы пациентов с односторонней и двусторонней ишемической нейрооптикопатией. Длительность наблюдения больных - 10 лет. Установлено, что при односторонней ишемической нейрооптикопатии наблюдается гиперметропическая анизометропия, при двусторонней - гиперметропи-

Введение. Передняя ишемическая нейрооптикопатия (ПИН) - заболевание, нередко ведущее к слепоте и инвалидности пациентов. Болеют люди трудоспособного возраста (40-60 лет), что составляет серьезную медико-социальную проблему $[7,8]$.

Этиология ПИН до конца не установлена [1]. Факторами, способствующими заболеванию, считают сахарный диабет, гипертоническую болезнь, атеросклероз, височный артериит и др.

Нами предложена концепция, согласно которой в возникновении ПИН играют роль рефракционно-аккомодационные факторы: некорригированная гиперметропия на фоне слабости аккомодации, превышающей возрастные нормы $[4,5$, 6]. Мы разработали метод лечения ПИН, блокирующий триггер заболевания - слабость аккомодации - путем циклоплегии [3]. В результате применения указанного метода удалось достичь высокой эффективности лечения больных [6].

ПИН бывает односторонней и двусторонней. В настоящее время отсутствуют доступные методы определения маркеров риска перехода ишемии зрительного нерва с одного глаза на парный. Предложенный генетический метод прогнозирования вероятности возникновения ишемической нейрооптикопатии [2] очень дорогостоящий, требует много времени и дает не всегда точные результаты.

Цель исследования. Разработать метод прогнозирования возможного двустороннего развития ПИН.

Материал и методы. Нами изучена рефракция двух групп пациентов: 1-ая группа (17 человек) - с односторонней ПИН; 2-ая группа (14 человек) - с двусторонней ПИН. Длительность наблюдения в обеих группах - до 10 лет. Группы были сопоставимы по возрасту, полу, тяжести местной и общей патологии.

Больным обеих групп в комплексе традиционного офтальмологического обследования проведено авторефрактометрию парных глаз на фоне циклоплегии.

(C) О.Д. Рудковская, 2013 ческая изометропия. Предложено считать наличие одинаковой рефракции на парных глазах при односторонней нейрооптикопатии маркером возможного двустороннего ишемического процесса в зрительных нервах.

Ключевые слова: ишемическая нейрооптикопатия, гиперметропия, слабость аккомодации.

Результаты исследования и их обсуждение. Установлено, что у всех пациентов была гиперметропия (слабой и средней степени). Очками больные не пользовались (кроме пресбиопической коррекции). У больных с односторонней ПИН патологический процесс развивался на глазу с большей аномалией рефракции. У пациентов с двусторонней ПИН данные авторефрактометрии были идентичны на парных глазах (таблицы № 1 и № 2).

При наличии некорригированной гиперметропической анизометропии на фоне слабости аккомодации существующая анизоаккомодация перегружает работу зрительного анализатора. В детском возрасте такая ситуация приводит к амблиопии глаза с большей аномалией рефракции. В зрелом возрасте на глазу с большей степенью гиперметропии (при наличии слабости аккомодации, превышающей возрастные нормы) может запускаться патологический процесс в зрительном нерве. Это компенсаторная реакция, направленная на снижение остроты зрения в худшем в рефракционном отношении глазу, уменьшения в нем напряжения аккомодации. В результате выравнивается аккомодационный стимул в парных глазах, что значительно облегчает работу зрительного анализатора.

При одинаковом строении оптического аппарата парных глаз при слабости аккомодации на фоне некорригированной гиперметропии патологический процесс (ПИН), как правило, развивается в обоих глазах (одинаковые анатомические предпосылки).

Такие пациенты должны быть предупреждены о возможности ПИН на обоих глазах. Больным целесообразно быть под диспансерным наблюдением окулиста, кардиолога, невропатолога; проводить самопроверку зрительных функций обоих глаз; тщательно корригировать аномалии рефракции; вести здоровый образ жизни (проводить укрепление организма и, соответственно, цилиарной мышцы - для профилактики слабости аккомодации и рецидивов заболевания). 
Таблица 1

Данные авторефрактометрии парных глаз у пациентов с односторонней передней ишемической нейрооптикопатией (фрагмент)

\begin{tabular}{|c|c|c|c|}
\hline \multirow{2}{*}{$\begin{array}{c}\text { № } \\
\text { п/п }\end{array}$} & \multirow{2}{*}{ ФиО } \\
\cline { 3 - 4 } & пациента & глаз, пораженный ПИН & Авторефрактометрия \\
\cline { 3 - 4 } & А-к С. & $\mathrm{sph}+2.25 \mathrm{D}$ & $\mathrm{sph}+1.0 \mathrm{D}$ \\
\hline & Б-к В. & $\mathrm{sph}+1.5 \mathrm{D}$ & $\mathrm{sph}+0.75 \mathrm{D}$ \\
\hline & Г-да Я. & $\mathrm{sph}+2.5 \mathrm{D}$ & $\mathrm{sph}+2.0 \mathrm{D}$ \\
\hline & Д-ка С. & $\mathrm{sph}+3.25 \mathrm{D}$ & $\mathrm{sph}+0.75 \mathrm{D}=\mathrm{cyl}-0.5 \mathrm{D}$ ax $102^{0}$ \\
\hline & Д-н О. & $\mathrm{sph}+2.0 \mathrm{D}=\mathrm{cyl}-0.5 \mathrm{D}$ ax $85^{0}$ & $\mathrm{sph}+2.0 \mathrm{D}=\mathrm{cyl}+1.0 \mathrm{D}$ ax $85^{0}$ \\
\hline & П-р Т. & $\mathrm{sph}+3.5 \mathrm{D}=\mathrm{cyl}+1.0$ ax $90^{0}$ & $\mathrm{sph}+1.5 \mathrm{D}$ \\
\hline & Р-ка Ю. & $\mathrm{sph}+3.0 \mathrm{D}$ & \\
\hline
\end{tabular}

Таблица 2

Данные авторефрактометрии парных глаз у пациентов с двусторонней передней ишемической нейрооптикопатией (фрагмент)

\begin{tabular}{|c|c|c|c|}
\hline \multirow{2}{*}{ № } & \multirow{2}{*}{ ФИО } & \multicolumn{2}{|c|}{ Авторефрактометрия } \\
\cline { 3 - 4 } & пациента & глаз, первым пораженный ПИН & глаз, вторым пораженный ПИН \\
\hline & К-к Д. & $\mathrm{sph}+1.25 \mathrm{D}$ & $\mathrm{sph} 1.25 \mathrm{D}$ \\
\hline & К-к К. & $\mathrm{sph}+1.5 \mathrm{D}$ & $\mathrm{sph}+1.5 \mathrm{D}$ \\
\hline & Л-к О. & $\mathrm{sph}+2.0 \mathrm{D}$ & $\mathrm{sph}+2.0 \mathrm{D}$ \\
\hline & М-й Л. & $\mathrm{sph}+1.5 \mathrm{D}=\mathrm{cyl}-1.0 \mathrm{D}$ ax $90^{0}$ & $\mathrm{sph}+1.5 \mathrm{D}=\mathrm{cyl}-1.0 \mathrm{D}$ ax $90^{0}$ \\
\hline & О-й В. & $\mathrm{sph}+2.75 \mathrm{D}$ & $\mathrm{sph}+2.75 \mathrm{D}$ \\
\hline & П-к Н. & $\mathrm{sph}+1.75 \mathrm{D}=\mathrm{cyl}-0.5 \mathrm{D}$ ax $84^{0}$ & $\mathrm{sph}+2.5 \mathrm{D}$ \\
\hline & Ш-б А. & $\mathrm{sph}+2.5 \mathrm{D}$ & $\mathrm{D}=0.5 \mathrm{D}$ ax $86^{0}$ \\
\hline
\end{tabular}

\section{Выводы}

1. В комплекс обследований пациентов с ишемической нейрооптикопатией необходимо включать авторефрактометрию парных глаз на фоне циклоплегии.

2. При наличии ишемической нейрооптикопатии одного глаза одинаковая рефракция парных глаз является маркером возможного двустороннего поражения ишемическим процессом зрительных нервов данного пациента.

\section{Литература}

1. Клініка Віллса. Діагностика і лікування очних хвороб: за ред. Д. Каллома та Б. Чанга. - Львів: Медицина світу, 1999. - С. 276-279.

2. Патент 2405455 Российская Федерация, МПК А 61810/00 GO1N33/53. Способ диагностики предрасположенности к ишемической нейрооптикопатии / Пономарева М.Н., Коновалова Н.А., Скляр Л.В.: заявитель и патентообладатель Государственное учреждение "Курганский областной госпиталь для ветеранов войн»; заявл. 15.09.2009; опубл. 10.12.2010. Бюл. № 12.

3. Патент 39589 Україна. МПК (2009) А 61F 9/00. Спосіб лікування ішемічної нейропатії зорового нерва / Руд- ковська О.Д.: заявник i патентовласник; заявл. 11.09.2007; опубл. 10.03.2009. Бюл. № 5.

4. Рудковська О.Д. Новий підхід до лікування ішемічної оптиконейропатії /О.Д.Рудковська: матеріали науково-практ. конференції за участю міжнар. спеціалістів [«Новітні проблеми офтальмології»]. - К., 2008. C. 168-169.

5. Рудковська О.Д. Спостереження випадку двобічної передньої ішемічної нейрооптикопатії, лікованої новим методом / О.Д. Рудковська // Клін. та експерим. патол. - 2009. - Т. VIII, № 1. - C. 116-118.

6. Рудковская О.Д. Использование циклоплегиков новый подход к лечению ишемии зрительного нерва / О.Д.Рудковская: материалы Междунар. научно-практ. конф. [«Актуальные вопросы современной медицины»]. - Новосибирск, 2013. - С. 56-58.

7. Treatment of nonarteritic anterior ischemic optic neuropathy / E.J. Atkins, B.B. Bruce, N.J. Newman [et al.] // Survey of Ophthalmology. - 2010, Jan.-Feb. - Vol. 55, № 1. - P. 47-63.

8. Ghaffariyeh A. Diod laser $810 \mathrm{~nm}$ as a potential treatment visual function in nonarteritic anterior ischemic optic neuropathy / A. Ghaffariyeh, N. Honarpishen, M.G. Khebreh [et al.] // Iranian J. of Medical hypotetheses and ideas. - 2011. - Vol. 5 (1). - P. 372-375. 


\section{ПРОГНОЗУВАННЯ ДВОБІЧНОГО УРАЖЕННЯ ЗОРОВИХ НЕРВІВ ІШЕМІЧНИМ ПРОЦЕСОМ}

\section{О.Д. Рудковська}

Резюме. Обстежено дві групи пацієнтів з однобічною і двобічною ішемічною нейрооптикопатією. Тривалість спостереження хворих - 10 років. Встановлено, що при однобічній ішемічній нейрооптикопатії спостерігається гіперметропічна анізометропія, при двобічній - гіперметропічна ізометропія. Запропоновано вважати наявність однакової рефракції на парних очах при однобічній нейрооптикопатії маркером можливого двобічного ішемічного процесу в зорових нервах.

Ключові слова: ішемічна нейрооптикопатія, гіперметропія, слабкість акомодації.

\section{PREDICTION OF A BILATERAL LESION OF THE OPTIC NERVES BY MEANS OF THE ISCHEMIC PROCESS}

\section{O.D. Rudkovskaya}

Abstract. We have examined 2 groups of patients with unilateral and bilateral ischemic neuroopticopathy. The duration of the patients' follow-up is 10 years.It has been established that hypermetropic anisometropia is observed in case of unilateral ischemic neuroopticopathy, whereas with the bilateral one - hypermetropic isometropia. It has been suggested to regard the presence of identical refraction on the paired eyes to be a marker of the bilateral ischemic process in the optic nerves in case of unilateral neuroopticopathy.

Key words: ischemic neuroopticopathy, hypermetropia, weakness of accommodation.

Bukovinian State Medical University (Chernivtsi)

Рецензент - проф. Ю.С. Роговий

Buk. Med. Herald. - 2013. - Vol. 17, № 2 (66). - P. 209-211

Надійшла до редакції 27.02.2013 року

(ㄱ О.Д. Рудковская, 2013 